\title{
Erratum zu: McColgan, Peter: Abschied vom Informationsmodell im Recht allgemeiner Geschäftsbedingungen
}

\section{Verlag Mohr Siebeck, Tübingen, 2020. XXIII, 360 Seiten. ISBN 978-3-16-158966-9}

\section{Christian Armbrüster}

Online publiziert: 6 . Juli 2020

(C) Springer-Verlag GmbH Deutschland, ein Teil von Springer Nature 2020

\section{Erratum zu:}

\section{ZVersWiss 2020}

https://doi.org/10.1007/s12297-020-00459-9

Liebe Leser,

der Artikel McColgan, Peter: Abschied vom Informationsmodell im Recht allgemeiner Geschäftsbedingungen. Verlag Mohr Siebeck, Tübingen, 2020. XXIII, 360 Seiten. ISBN 978-3-16-158966-9.

von Christian Armbrüster wurde ursprünglich am 15.05.2020 ohne „Open Access“ online auf der Internetplattform des Verlags publiziert.

Der Autor hat sich jedoch nachträglich für eine „Open Access“-Veröffentlichung entschieden. Das Urheberrecht des Artikels wurde deshalb im Juli 2020 in @ Der/die Autor(en) 2020 geändert.

Der Artikel wird nun unter der Namensnennung 4.0 International (https:// creativecommons.org/licenses/by/4.0/deed.de) veröffentlicht, welche die Nutzung, Vervielfältigung, Bearbeitung, Verbreitung und Wiedergabe in jeglichem Medium und Format erlaubt, sofern Sie den/die ursprünglichen Autor(en) und die Quelle ordnungsgemäß nennen, einen Link zur Creative Commons Lizenz beifügen und angeben, ob Änderungen vorgenommen wurden.

Die Online-Version des Originalartikels ist unter https://doi.org/10.1007/s12297-020-00459-9 zu finden.

C. Armbrüster $(\bowtie)$

Fachbereich Rechtswissenschaft, Freie Universität Berlin, Van’t-Hoff-Str. 8, 14195 Berlin,

Deutschland

E-Mail: c.armbruester@fu-berlin.de 
„Die ursprüngliche Version dieses Artikels wurde aufgrund der rückwirkenden Open-Access-Bestellung nicht überarbeitet.“ 